\title{
The Effect of a Trapping Procedure on the Stress Response of Wild Rainbow Trout
}

\author{
Shaun P. Clements*1 and Brendan J. Hicks \\ Centre for Biodiversity and Ecology Research, \\ Department of Biological Sciences, \\ University of Waikato, Private Bag 3105, \\ Hamilton, New Zealand \\ JOHN F. CARRAGHER ${ }^{2}$ \\ Animal Behaviour and Welfare Research Centre, \\ AgResearch, Ruakura Agricultural Centre, \\ Private Bag 3123, Hamilton, New Zealand \\ Michel Dedual \\ Department of Conservation, Tongariro/Taupo Conservancy, \\ Private Bag, Turangi, New Zealand
}

\begin{abstract}
Fish traps are a common research and management tool in which fish are subjected to procedures that elicit a stress response in other contexts. The effects of trapping on the stress response of sexually mature, wild rainbow trout Oncorhynchus mykiss were investigated during their upstream spawning migration by measuring concentrations of plasma cortisol, lactate, and glucose. Males had significantly lower basal plasma cortisol concentrations $(6.1 \pm 0.8 \mathrm{ng} / \mathrm{mL}$ [mean $\pm \mathrm{SE}])$ than females $(21.4 \pm 5.9 \mathrm{ng} / \mathrm{mL})$. Similarly, the plasma cortisol response in males was significantly lower than that in females for all experiments. Fish working the barrier before entering the trap had increased concentrations of plasma cortisol. Confinement in the trap also induced a stress response. Plasma cortisol concentrations increased to $185.1 \pm 40.9 \mathrm{ng} / \mathrm{mL}$ in males and $549.1 \pm 60.1 \mathrm{ng} / \mathrm{mL}$ in females after confinement for $1 \mathrm{~h}$. After processing, the magnitude of the stress response and the relative duration of recovery was less in fish that were confined longer in the trap. However, resting cortisol concentrations in females were not reached after 40 $\mathrm{h}$ of recovery in either group. Recovery to resting concentrations of plasma lactate occurred within $15 \mathrm{~h}$ after processing. In contrast, concentrations of plasma glucose remained significantly elevated at $40 \mathrm{~h}$ after processing. Postspawning fish had significantly lower plasma concentrations of cortisol, glucose, and lactate following application of an extreme stressor compared with prespawning fish. Based on the results of this study, we conclude that the trapping procedure induces a severe and prolonged stress response in wild rainbow trout.
\end{abstract}

In many countries fish are trapped to provide data for fishery management, often at critical life stages (e.g., spawning adults or out-migrant juveniles). Based on the response of fish to other forms of stressors (e.g., handling or hypoxia), trapping is also likely to elicit a stress response. However, to our knowledge there is no information about the magnitude or duration of such a re-

\footnotetext{
* Corresponding author: clemensh@onid.orst.edu

1 Present address: Oregon Cooperative Fish and Wildlife Research Unit, Department of Fisheries and Wildlife, 104 Nash Hall, Oregon State University, Corvallis, Oregon 97331, USA.

2 Present address: School of Biological Sciences, Faculty of Sciences and Engineering, Flinders University of South Australia, GPO Box 2100, Adelaide 5001, Australia.
}

Received May 10, 2000; accepted January 6, 2002 sponse. An understanding of the physiological responses of wild fish to trapping would be of value given the well-documented effects of the stress response on domesticated fish (e.g., WendalaarBonga 1997). Wild fish may respond differently to stressors because of genetic or environmental differences. Furthermore, indirect selection within hatchery fish may have resulted in strains that have a reduced response to stressors. Similarly, hatchery fish may show differences in avoidance behavior towards predators compared with wild fish.

The effects of trapping may also extend to postspawning fish in populations where return migrants must be passed through the upstream barrier. For rainbow trout Oncorhynchus mykiss, repeat spawners may constitute a significant portion of the spawning population. Despite the importance of repeat spawners, little is known about the phys- 
iological effects of additional stressors and the factors contributing to the survival of postspawning fish. Furthermore, management procedures are often directed at protecting prespawning fish and ignore the health of postspawners. It is likely that postspawning fish will have a reduced capacity for coping with further challenges, given that these fish expend considerable energy reproducing.

Physiological research on stress has focused on the response of the hypothalamic-pituitaryinterrenal (HPI) axis and the resultant elevation of circulating corticosteroids. As a result of this activity, cumulative effects of sublethal stressors may lead to a reduced ability to cope with subsequent stressors (Barton et al. 1986; Sigismondi and Weber 1988), reduced recruitment to successive life stages (Adams et al. 1985), or death, even though the contributing factors may not individually exceed the fish's physiological limits (Donaldson 1981; Carmichael 1984; Barton et al. 1986).

Our study was designed to determine whether trapping of wild, mature rainbow trout results in a stress response and, if so, the nature of the response. Trapping usually consists of several elements that may represent discrete stressors to the fish. Our study measured the stress response of fish to the entire operation and to three elements: the barrier to upstream migration, confinement in the holding cage, and processing (netting, measuring and fin clipping). To evaluate the probable effects of downstream passage through the barrier, the stress response of postspawning fish was also evaluated. Measurements of plasma cortisol, lactate, and glucose were made as indicators of the primary and secondary stress response of these fish to trapping.

\section{Methods}

Experimental fish.-Blood was sampled from 264 rainbow trout (90 males, 174 females; fork length $541 \pm 13 \mathrm{~mm}$ [mean $\pm \mathrm{SE}$; weight, 1,980 $\pm 9 \mathrm{~g}$ ) during their upstream spawning migration (April-October 1995). Sampling was conducted in the Whitikau Stream, a tributary of the Tongariro River (North Island, New Zealand). Mean $(N=$ 20) physicochemical characteristics of the river were as follows: $\mathrm{pH}, 7.11 \pm 0.08$; dissolved oxygen saturation, $94.30 \pm 2.0 \%$; conductivity, $42.56 \pm 1.01 \mu \mathrm{S} / \mathrm{cm}$; and total dissolved solids, $21.28 \pm 0.58 \mathrm{mg} / \mathrm{L}$. This river is closed to angling year round. Blood was also sampled from 44 postspawned rainbow trout ( 21 male, 23 female) that were captured above the trap.

Trap design.- The trap consisted of a wire net- ting barrier (width, $10 \mathrm{~m}$ ) placed across the river and anchored in the riverbed. At one end of the barrier a rectangular cage constructed of wire netting over a galvanized metal frame $(2.2 \mathrm{~m}$ long $\times$ $1.4 \mathrm{~m}$ wide $\times 1 \mathrm{~m}$ deep) was placed into a gap. The downstream end of the cage was a V-shaped funnel, the apex facing upstream. Fish that were swimming along the barrier attempting to find a passage upstream eventually swam across to the cage and into the $\mathrm{V}$, where they could enter the cage through an 11-cm gap in the apex.

Sampling procedure.-The experiments in this study were conducted between April and October 1995. This was necessary because of the variable environment, the nature of the spawning run, and the constraints of the experimental design. Blood samples were obtained from unanaesthetised fish that were restrained ventral side up in a prewetted, plastic-lined foam wedge. A mixed arteriovenous blood sample (about $1.5 \mathrm{~mL}$ ) from a caudal puncture was obtained with a $10-\mathrm{mL}$ preheparinized (sodium heparin) Vacutainer and 18-gauge needle. Each fish was sampled only once, then immediately released into the river. The blood sample was centrifuged within $20 \mathrm{~min}$. The resultant plasma was separated and stored frozen on ice for up to $3 \mathrm{~d}$ before storage at $-20^{\circ} \mathrm{C}$.

Controls.-To evaluate control levels of selected stress response indices, 25 rainbow trout (10 males, 15 females) were angled in waters $300-700$ $\mathrm{m}$ downstream of the trap. Each fish was sampled as rapidly as possible (2-3 min) so that their blood measurements closely approximated those in the unstressed condition (Sumpter et al. 1986). Only one to two fish were landed from a pool at the same time to avoid sampling fish that had been disturbed by the presence of the angler (Pankhurst and Dedual 1994). To assess whether baseline conditions of the stress response indices were changing over time, angling for control fish was conducted one to two times per month (see Table 1 for dates). On each occasion blood was sampled from four to six fish.

Effect of an extreme stressor.-To assess whether the ability of the fish to respond to a stressor was changing over time and to provide a basis for the comparison of the effects of trapping, we used an extreme stressor treatment. The treatment consisted of dipnetting three fish that had been in the cage for less than $15 \mathrm{~min}$ and transferring them to a 50-L white plastic container half-filled with water. We subsequently placed the container in Whitikau Stream. The ends of the container were perforated to permit flow (Pickering and Pottinger 
TABLE 1.-Control concentrations of plasma glucose $(\mathrm{mg} / \mathrm{dL})$, lactate $(\mathrm{mmol} / \mathrm{L})$, and cortisol $(\mathrm{ng} / \mathrm{mL})$ in wild rainbow trout caught in the Whitikau Stream, New Zealand, in 1994.

\begin{tabular}{|c|c|c|c|}
\hline Date & Glucose & Lactate & Cortisol \\
\hline \multicolumn{4}{|c|}{ Females } \\
\hline 20 Jun & 80.0 & 1.6 & 7.0 \\
\hline $20 \mathrm{Jun}$ & 75.0 & 0.4 & 19.5 \\
\hline $20 \mathrm{Jun}$ & 76.0 & 1.4 & 22.5 \\
\hline 21 Jun & 87.0 & 1.0 & 27.5 \\
\hline $21 \mathrm{Jun}$ & 69.0 & 0.8 & 2.5 \\
\hline $7 \mathrm{Jul}$ & 61.0 & 0.5 & \\
\hline $7 \mathrm{Jul}$ & 56.0 & 1.4 & 4.5 \\
\hline $8 \mathrm{Jul}$ & 91.0 & 0.6 & 29.2 \\
\hline 16 Aug & 72.0 & 1.0 & 82.5 \\
\hline 16 Aug & 79.0 & 0.9 & 52.5 \\
\hline 16 Aug & 56.0 & 0.3 & 11.3 \\
\hline $21 \mathrm{Sep}$ & 74.0 & 1.0 & 15.8 \\
\hline $21 \mathrm{Sep}$ & 80.0 & 0.8 & 5.8 \\
\hline 21 Sep & 63.0 & 1.2 & 6.8 \\
\hline 5 Oct & 69.0 & 0.9 & 12.5 \\
\hline \multicolumn{4}{|c|}{ Males } \\
\hline $21 \mathrm{Jun}$ & & & 2.5 \\
\hline $7 \mathrm{Jul}$ & & & 7.7 \\
\hline $7 \mathrm{Jul}$ & & & 9.8 \\
\hline $8 \mathrm{Jul}$ & & & 9.6 \\
\hline 16 Aug & & & 6.7 \\
\hline 16 Aug & & & 4.5 \\
\hline $23 \mathrm{Sep}$ & 75.0 & 1.3 & 5.0 \\
\hline $23 \mathrm{Sep}$ & 61.0 & 1.7 & 7.5 \\
\hline 5 Oct & 75.0 & 0.9 & 2.5 \\
\hline $5 \mathrm{Oct}$ & 61.0 & 0.3 & 5.5 \\
\hline
\end{tabular}

1987). The fish were confined in the container for $1 \mathrm{~h}$ and were periodically chased by hand to elevate the stress response. The blood of each fish was then sampled, and the fish was released. This experiment was repeated eight times over the 6month period at approximately 3 -week intervals (see Table 2 for dates). In total, blood was sampled from 22 rainbow trout ( 8 males, 14 females).

Effect of the barrier.-To determine whether the barrier is perceived as a stressor, 20 rainbow trout (11 males, 9 females) that were observed swimming along the barrier were dipnetted out immediately after entering the trap, and their blood was sampled. This was done to avoid any confounding effect due to confinement. We estimated that most fish spent about 15-20 min at the barrier before entering the trap.

Effect of confinement duration.-To test the effect of the duration of confinement in the trap, 64 rainbow trout ( 30 males, 34 females) were trapped and confined in the trap for 1,5 , or $10 \mathrm{~h}$. Five to seven fish were confined at a time. There were nine trials in total (three for each confinement period). During each trial all fish entered the trap within 15 min of each other for the 1-h confinement and
TABLE 2.-Extreme stressor concentrations of plasma glucose $(\mathrm{mg} / \mathrm{dL})$, lactate $(\mathrm{mmol} / \mathrm{L})$, and cortisol $(\mathrm{ng} / \mathrm{mL})$ in wild rainbow trout caught in the Whitikau Stream, New Zealand, in 1994.

\begin{tabular}{|c|c|c|c|}
\hline Date & Glucose & Lactate & Cortisol \\
\hline \multicolumn{4}{|c|}{ Females } \\
\hline 4 Jun & 106 & 6.3 & 500 \\
\hline 4 Jun & 128 & 9.4 & 375 \\
\hline 21 Jun & 53 & 2.1 & 275 \\
\hline $3 \mathrm{Jul}$ & 81 & 5.2 & 475 \\
\hline $3 \mathrm{Jul}$ & 86 & 5.6 & 425 \\
\hline $28 \mathrm{Jul}$ & 116 & 5.9 & 625 \\
\hline 15 Aug & 98 & 5.1 & 450 \\
\hline 15 Aug & 99 & 2.9 & 500 \\
\hline $18 \mathrm{Sep}$ & 116 & 10.2 & 425 \\
\hline $18 \mathrm{Sep}$ & 151 & 9.9 & 575 \\
\hline $18 \mathrm{Sep}$ & 75 & 1.3 & 275 \\
\hline $28 \mathrm{Sep}$ & 92 & 2.1 & 375 \\
\hline 7 Oct & 115 & 9.1 & 575 \\
\hline 7 Oct & 57 & 4 & 200 \\
\hline \multicolumn{4}{|c|}{ Males } \\
\hline 4 Jun & 102 & 11.1 & 325 \\
\hline 21 Jun & 180 & 4.6 & 200 \\
\hline $3 \mathrm{Jul}$ & 86 & 4.8 & 300 \\
\hline $28 \mathrm{Jul}$ & 108 & 5.3 & 150 \\
\hline 15 Aug & 112 & 5.6 & 350 \\
\hline 28 Sep & 130 & 4.1 & 275 \\
\hline 28 Sep & 60 & 5.6 & 150 \\
\hline 7 Oct & 90 & 1.8 & 115 \\
\hline
\end{tabular}

within $30 \mathrm{~min}$ for the 5-h and 10-h confinements. The entrance to the cage was then blocked. Following the confinement period the blood of each fish was sampled within $5 \mathrm{~min}$, and the fish was released.

Effect of processing.-Ten female rainbow trout were processed immediately after entering the trap to avoid any confounding effect of confinement. Processing involved netting the fish out of the trap into a canvas bag, clipping the pectoral fin, determining the sex and stage of maturity, measuring length and weight, and looking for evidence of previous clips or tags. This procedure took about $1 \mathrm{~min} / \mathrm{fish}$. The fish were then transferred to a recovery enclosure for $1 \mathrm{~h}$ (see below for description); at the end of the hour, they were netted and within 2 min their blood was sampled. Only females were sampled because too few males were available at the time of the experiment. Four fish were sampled on 15 August and 3 fish were sampled on both 26 and 28 September. The results of this experiment were compared with those for control fish, fish challenged by an extreme stressor, and fish confined for $1 \mathrm{~h}$ without processing.

Recovery from the trapping procedure.-To determine the rate of recovery from the trapping procedure, groups of four to six rainbow trout ( 33 
males, 44 females) were trapped and confined in the cage for either 1 or $10 \mathrm{~h}$. Individual fish entered the trap within 15 min of each other for the 1-h confinement and within $30 \mathrm{~min}$ for the 10 -h confinement. The entrance to the cage was then blocked to prevent other fish entering. Following confinement the fish were processed as described previously. The fish were then transferred manually $(<2 \mathrm{~min})$ in a $50-\mathrm{L}$ plastic container to one of two enclosed stream reaches where they were left to recover for $1,5,15,24$, or $40 \mathrm{~h}$.

The enclosures were constructed by damming side channels of the main river with rocks and logs at locations 50 and $150 \mathrm{~m}$ from the trap site. The dimensions of these recovery areas were $30.0 \times$ $1.7 \times 0.5 \mathrm{~m}$ (length $\times$ mean width $\times$ maximum depth) and $40.0 \times 2.0 \times 0.7 \mathrm{~m}$, respectively. Both enclosures had runs, riffles, pools, and cover from overhanging bushes and rocky outcrops. Several fish were observed in the enclosures before and between experiments when part of the rock and wooden dam was dismantled, indicating that the enclosures provided suitable habitat for trout. Fish were not disturbed by humans while recovering in these areas. All the fish in a recovery area were sampled at a single time. At the end of the appropriate recovery period, the fish were shepherded to one end of the enclosure, netted, and their blood was sampled within $5 \mathrm{~min}$ of the initial disturbance. For each combination of confinement and recovery times there were two trials. Unfortunately, not all predetermined times could be sampled during the experimental period because of the lack of fish, flooding, and volcanic ashfall. No experiments were performed following the volcanic eruption of Mt. Ruapehu or during a flood. Thus, no fish confined for $1 \mathrm{~h}$ and recovered for $5 \mathrm{~h}$ or confined for $10 \mathrm{~h}$ and recovered for $24 \mathrm{~h}$ were sampled. Thus, the sample sizes for females confined for $1 \mathrm{~h}$ and $10 \mathrm{~h}$, respectively, were as follows: 6 and 7 ( $1 \mathrm{~h}$ of recovery), 0 and 7 ( $5 \mathrm{~h}$ of recovery), 5 and 4 (15 h of recovery), 4 and 0 (24 $\mathrm{h}$ of recovery), and 5 and 6 (40 h of recovery). The corresponding sample sizes for males were 6 and 5 ( $1 \mathrm{~h}$ of recovery), 0 and 1 ( $5 \mathrm{~h}$ of recovery), 5 and 5 (15 h of recovery), 4 and 0 ( $24 \mathrm{~h}$ of recovery), and 6 and 4 (40 h of recovery).

Stress response in prespawning versus postspawning fish.-Rainbow trout that had spawned (kelts) were caught by angling (10 males, $12 \mathrm{fe}-$ males) in the stream above the trap. The capture protocol was identical to that used to capture prespawning control fish. To measure the ability of postspawning fish to undergo a stress response, 22 fish (11 of both sexes) that had spawned were dipnetted $(<5 \mathrm{~min})$ from the river above the trap and confined according to the protocol described for sampling fish challenged by an extreme stressor.

Blood analysis.-Plasma cortisol concentration was determined by ${ }^{125}$ I radioimmunoassay following extraction in ethyl acetate using methods of Ingram et al. (1994). The antibody used has the following cross reactivities: $17-\alpha$ hydroxyprogesterone 10.0\%; 11-deoxycortisol 5.7\%; cortisone $1.2 \%$; and corticosterone $0.8 \%$. Samples were assayed in duplicate (mean interassay coefficient of variation $(\mathrm{CV})=13.4 \%)$. Plasma lactate was analyzed in duplicate, and concentrations were determined using reagents and standards from Abbott and Boehringer Mannheim on a Hitachi 717 Auto Analyzer. Plasma glucose concentrations were determined using a Glucose Analyzer 2, glucose reagent and standards (Beckman). Samples were assayed in duplicate. For all assays a CV between duplicates of less than 5\% was considered acceptable.

Statistical analysis.- Tests for significance were performed using analysis of variance (ANOVA). Where differences were significant, multiple comparisons among means were based on Student's $t$ statistic with a Bonferroni adjustment of the observed significance level to allow for the multiple comparisons. There were no differences between trials for any of the experiments; therefore, the data were pooled for final analysis. Normality of the data were tested by comparison with normal probability plots. With two exceptions, all data were normal, and means are reported as \pm 1 SE. Analyses were performed with SYSTAT (SPSS 2000), and significance was set at $\alpha=0.05$.

\section{Results}

Mean plasma cortisol concentrations in prespawning fish were always significantly lower in males than in females; thus, data for plasma cortisol are analyzed and presented separately for each sex. There was no difference between sexes for plasma lactate or glucose, so these data were combined.

\section{Controls}

There was no difference over time in basal concentrations of cortisol (males: $F=3.17$, $\mathrm{df}=9$, $P=0.143$; females: $F=1.24, \mathrm{df}=13, P=0.388$ ), lactate $(F=0.95, \mathrm{df}=18, P=0.501)$, or glucose $(F=1.88, \mathrm{df}=18, P=0.169$; Table 1$)$. Therefore, we pooled the data and used these measures for comparison throughout the study. Plasma cortisol 
TABLE 3.-Mean plasma cortisol $(\mathrm{ng} / \mathrm{mL})$, lactate $(\mathrm{mmol} / \mathrm{L})$, and glucose $(\mathrm{mg} / \mathrm{dL})$ concentrations $(\mathrm{SE} ; N)$ in rainbow trout sampled immediately after capture by angling (control) and in fish that were working the barrier, confined in the trap for 1,5 , or $10 \mathrm{~h}$, processed upon entry into the trap and allowed to recover for $1 \mathrm{~h}$, or challenged by an extreme stressor for $1 \mathrm{~h}$. Mean values within a row that share a common lowercase letter are not different (analysis of variance [ANOVA] with multiple comparisons using a Bonferroni adjustment; $P<0.05$ ).

\begin{tabular}{|c|c|c|c|c|c|c|c|c|}
\hline \multirow[b]{2}{*}{ Substance } & \multirow[b]{2}{*}{ Sex } & \multirow[b]{2}{*}{ Control } & \multirow[b]{2}{*}{ Barrier } & \multicolumn{3}{|c|}{ Time in trap (h) } & \multirow[b]{2}{*}{ Processed } & \multirow{2}{*}{$\begin{array}{l}\text { Extreme } \\
\text { stressor }\end{array}$} \\
\hline & & & & 1 & 5 & 10 & & \\
\hline \multirow[t]{2}{*}{ Cortisol } & Males & $\begin{array}{c}6.1 \mathrm{z} \\
(0.8 ; 10)\end{array}$ & $\begin{array}{c}83.5 \text { y } \\
(13.9 ; 11)\end{array}$ & $\begin{array}{l}173.7 \mathrm{yx} \\
(43.4 ; 11)\end{array}$ & $\begin{array}{l}130.9 \text { yx } \\
(26.3 ; 11)\end{array}$ & $\begin{array}{l}138.6 \text { yx } \\
(26.5 ; 7)\end{array}$ & & $\begin{array}{l}233.1 \mathrm{x} \\
(32.0 ; 8)\end{array}$ \\
\hline & Females & $\begin{array}{l}21.4 \mathrm{z} \\
(5.9 ; 14)\end{array}$ & $\begin{array}{c}144.8 \text { y } \\
(22.5 ; 9)\end{array}$ & $\begin{array}{l}532.6 \mathrm{w} \\
(58.3 ; 14)\end{array}$ & $\begin{array}{l}380.1 \mathrm{xW} \\
(73.1 ; 11)\end{array}$ & $\begin{array}{l}277.8 \text { yx } \\
(35.9 ; 11)\end{array}$ & $\begin{array}{l}263.4 \text { yx } \\
(18.5 ; 10)\end{array}$ & $\begin{array}{l}432.1 \mathrm{xw} \\
(33.1 ; 14)\end{array}$ \\
\hline Lactate & Sexes combined & $\begin{array}{c}0.94 \mathrm{z} \\
(0.09 ; 19)\end{array}$ & $\begin{array}{r}1.35 \mathrm{z} \\
(0.17 ; 20)\end{array}$ & $\begin{array}{c}2.21 \mathrm{y} \\
(0.22 ; 22)\end{array}$ & $\begin{array}{c}1.00 \mathrm{z} \\
(0.09 ; 19)\end{array}$ & $\begin{array}{c}0.97 \mathrm{z} \\
(0.13 ; 18)\end{array}$ & $\begin{array}{c}5.22 \times \\
(0.18 ; 10)\end{array}$ & $\begin{array}{c}5.54 \mathrm{x} \\
(0.60 ; 22)\end{array}$ \\
\hline Glucose & Sexes combined & $\begin{array}{l}71.6 \mathrm{z} \\
(2.3 ; 19)\end{array}$ & $\begin{array}{c}72.1 \mathrm{z} \\
(3.6 ; 20)\end{array}$ & $\begin{array}{l}74.6 \mathrm{z} \\
(2.6 ; 22)\end{array}$ & $\begin{array}{l}76.4 \mathrm{z} \\
(3.2 ; 19)\end{array}$ & $\begin{array}{l}88.3 \mathrm{zy} \\
(5.3 ; 18)\end{array}$ & $\begin{array}{l}75.1 \mathrm{z} \\
(3.1 ; 10)\end{array}$ & $\begin{array}{l}101.9 \mathrm{y} \\
(6.4 ; 22)\end{array}$ \\
\hline
\end{tabular}

was significantly lower in males than females $(F$ $=4.69$, $\mathrm{df}=23, P=0.042)$; however, there was no effect of sex on plasma levels of lactate and glucose (Table 3).

\section{Extreme Stressor}

There was no difference over time in the magnitude of the stress response for concentrations of cortisol (males: $F=1.05$, df $=7, P=0.626$; females: $F=0.05$, df $=13, P=0.805)$, lactate $(F=1.22, \mathrm{df}=21, P=0.356)$, or glucose $(F=$ $0.40, \mathrm{df}=21, P=0.887$; Table 2). Therefore, we pooled the data and used these measures for comparison throughout the study. Plasma cortisol concentrations increased by at least 20 -fold compared with control fish, reaching $233.0 \pm 31.0 \mathrm{ng} / \mathrm{mL}$ in males and $432.0 \pm 33.0 \mathrm{ng} / \mathrm{mL}$ in females (Table $3)$.

\section{Effect of the Barrier}

Fish that were sampled after swimming along the barrier had significantly higher mean plasma cortisol concentrations compared with control fish (males: $F=8.33$, df $=57, P<0.001$; females: $F=19.12, \mathrm{df}=82, P<0.001)$. Plasma concentrations of lactate and glucose were not different from controls.

\section{Effect of Confinement Duration}

Plasma cortisol concentrations in males increased during the first hour of confinement, peaking at $185.1 \pm 40.9 \mathrm{ng} / \mathrm{mL}$ (overall $F=8.33$, df $=57 ; P<0.001 ;$ Table 3 ). Similarly, mean plasma cortisol concentrations in females increased following entry to the trap and reached a peak of $549.1 \pm 60.1 \mathrm{ng} / \mathrm{mL}$ after $1 \mathrm{~h}$ of confinement (overall $F=19.12$, df $=82 ; P<0.001$ ). In contrast to males, concentrations of cortisol in females declined significantly between 1 -h and 10 -h confinements $(P<0.001)$. For all confinement periods, and for both sexes, plasma cortisol concentrations were not significantly different from those measured in fish following the extreme stressor.

Mean plasma lactate concentration was significantly elevated above the angled control concentrations following $1 \mathrm{~h}$ of confinement (overall $F$ $=40.81, \mathrm{df}=129, P=0.046)$ but were similar to control concentrations after $5 \mathrm{~h}$ of confinement in the trap (Table 3). Plasma lactate for all confinement periods was significantly lower than in fish subject to the extreme stressor. Plasma glucose concentrations tended to increase during confinement but were not significantly different from controls at any time.

\section{Effect of Processing}

There was no difference between the three sampling dates for plasma concentrations of cortisol $(F=0.01, \mathrm{df}=9, P=0.993)$, lactate $(F=0.28$, df $=9, P=0.764)$, or glucose $(F=2.73$, df $=$ $9, P=0.133)$. The mean plasma cortisol concentration in females $1 \mathrm{~h}$ postprocessing (without confinement) was significantly higher than concentrations in control fish (overall $F=19.12$, df $=82$; $P<0.001)$ but was lower than concentrations in fish confined for $1 \mathrm{~h}$ in the trap $(P<0.001)$ and in fish challenged by the extreme stressor $(P=$ 0.026 ).

In contrast, the mean concentration of plasma lactate was significantly higher than in controls (overall $F=40.81$, df $=129, P<0.001$ ) and fish confined for $1 \mathrm{~h}$ in the trap $(P<0.001)$ but was not different from fish challenged by the extreme stressor. 
TABLE 4.-Mean plasma cortisol ( $\mathrm{ng} / \mathrm{mL})$, lactate $(\mathrm{mmol} / \mathrm{L})$, and glucose $(\mathrm{mg} / \mathrm{dL})$ concentrations $(\mathrm{SE} ; N)$ in pre- and postspawning rainbow trout. Fish were sampled immediately after capture by angling (control) or after the extreme stressor treatment. Data for prespawning fish are the same as in Table 1 but are presented again for comparison. Mean values within a row that share a common lowercase letter are not different (three-way ANOVA with multiple comparisons using a Bonferroni adjustment; $P<0.05$ ).

\begin{tabular}{|c|c|c|c|c|c|}
\hline \multirow[b]{2}{*}{ Substance } & \multirow[b]{2}{*}{ Sex } & \multicolumn{2}{|c|}{ Postspawning } & \multicolumn{2}{|c|}{ Prespawning } \\
\hline & & Control & $\begin{array}{l}\text { Extreme } \\
\text { stressor }\end{array}$ & Control & $\begin{array}{c}\text { Extreme } \\
\text { stressor }\end{array}$ \\
\hline \multirow[t]{2}{*}{ Cortisol } & Male & $\begin{array}{c}19.3 \mathrm{z} \\
(6.9 ; 9)\end{array}$ & $\begin{array}{c}97.7 \mathrm{y} \\
(18.1 ; 10)\end{array}$ & $\begin{array}{c}6.1 \mathrm{z} \\
(0.8 ; 10)\end{array}$ & $\begin{array}{r}233.1 \mathrm{x} \\
(32.0 ; 8)\end{array}$ \\
\hline & Female & $\begin{array}{c}11.0 \mathrm{z} \\
(3.5 ; 12)\end{array}$ & $\begin{array}{c}165.8 \text { y } \\
(41.0 ; 12)\end{array}$ & $\begin{array}{c}21.4 \mathrm{z} \\
(5.9 ; 14)\end{array}$ & $\begin{array}{c}432.1 \mathrm{x} \\
(33.1 ; 14)\end{array}$ \\
\hline Lactate & Sexes combined & $\begin{array}{c}0.9 \mathrm{z} \\
(0.1 ; 23)\end{array}$ & $\begin{array}{c}3.1 \mathrm{y} \\
(0.4 ; 22)\end{array}$ & $\begin{array}{c}0.9 \mathrm{z} \\
(0.1 ; 19)\end{array}$ & $\begin{array}{c}5.5 \mathrm{x} \\
(0.6 ; 22)\end{array}$ \\
\hline Glucose & Sexes combined & $\begin{array}{c}61.5 \mathrm{z} \\
(1.9 ; 21)\end{array}$ & $\begin{array}{c}66.4 \mathrm{z} \\
(4.2 ; 22)\end{array}$ & $\begin{array}{c}71.6 \mathrm{z} \\
(2.3 ; 19)\end{array}$ & $\begin{array}{l}101.9 \mathrm{y} \\
(6.4 ; 22)\end{array}$ \\
\hline
\end{tabular}

\section{Recovery from the Trapping Procedure}

Plasma cortisol concentrations in female fish confined for $1 \mathrm{~h}$ declined significantly between 15 and $40 \mathrm{~h}$ after processing (overall $F=20.656$, df $=42, P=0.015$ ); however, levels were still 10 times higher $(214.0 \pm 16.0 \mathrm{ng} / \mathrm{mL})$ than in control fish (21.4 $\pm 5.9 \mathrm{ng} / \mathrm{mL}$; Figure 1A). Plasma cortisol concentrations in female fish confined for 10 $\mathrm{h}$ reached a measured peak following $5 \mathrm{~h}$ of recovery (overall $F=24.045$, df $=43, P<0.001$ ). Concentrations declined significantly between 5 and $40 \mathrm{~h}(P<0.001)$ but remained at least five times higher than resting levels after $40 \mathrm{~h}$ of recovery.

Similarly, plasma cortisol concentrations in male fish confined for $10 \mathrm{~h}$ reached a measured peak following $5 \mathrm{~h}$ of recovery, although this value is based on a sample of one fish (Figure 1B). Concentrations declined significantly between 5 and 40 h (overall $F=47.983$, df $=29, P<0.001$ ) and were similar to levels in control fish at this time. Plasma cortisol concentrations in male fish that were confined for $1 \mathrm{~h}$ did not change significantly during recovery but were not significantly different from control levels after $40 \mathrm{~h}$ recovery.

Plasma cortisol concentrations in female fish confined for $10 \mathrm{~h}$ were significantly lower than in female fish confined for $1 \mathrm{~h}$ after 1,15 , and $40 \mathrm{~h}$ of recovery $(P=0.006,0.031$, and 0.003 ; respectively). Similarly, for males, levels were significantly lower in fish confined for $10 \mathrm{~h}$ after 40 h of recovery $(P<0.001)$. No comparison was possible for 5 and $24 \mathrm{~h}$ postprocessing because of a lack of data.

Plasma lactate concentrations changed significantly during recovery following confinement in the trap for $1 \mathrm{~h}(F=77.394, \mathrm{df}=75)$ or $10 \mathrm{~h}(F$
$=46.237, \mathrm{df}=69)$. Concentrations were significantly elevated after $1 \mathrm{~h}$ of recovery in both treatment groups $(1 \mathrm{~h}: P<0.001 ; 10 \mathrm{~h}: P<0.001$; Figure 2A). Furthermore, the levels at this time were significantly higher in fish that had only been

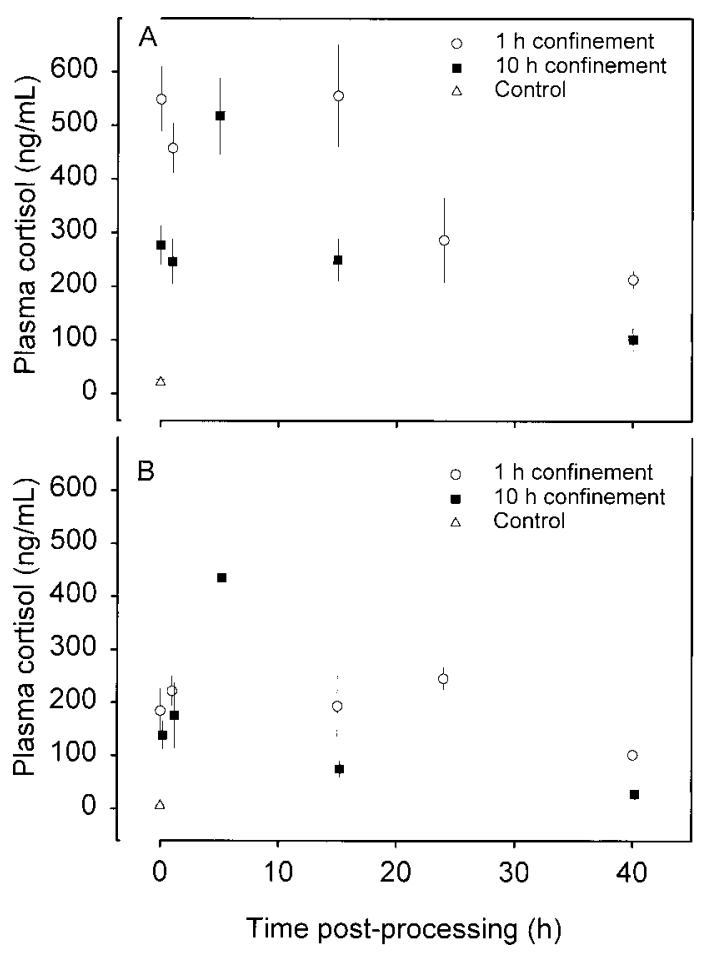

FIGURE 1.-Plasma cortisol concentrations (mean \pm $\mathrm{SE}$ ) in (A) female and (B) male rainbow trout during recovery from trapping after 1 or $10 \mathrm{~h}$ of confinement; control fish were not confined and were angled downstream of the barrier and trap. Concentrations at the end of confinement are shown as $0 \mathrm{~h}$. All fish were from the Whitikau Stream in northern New Zealand. 


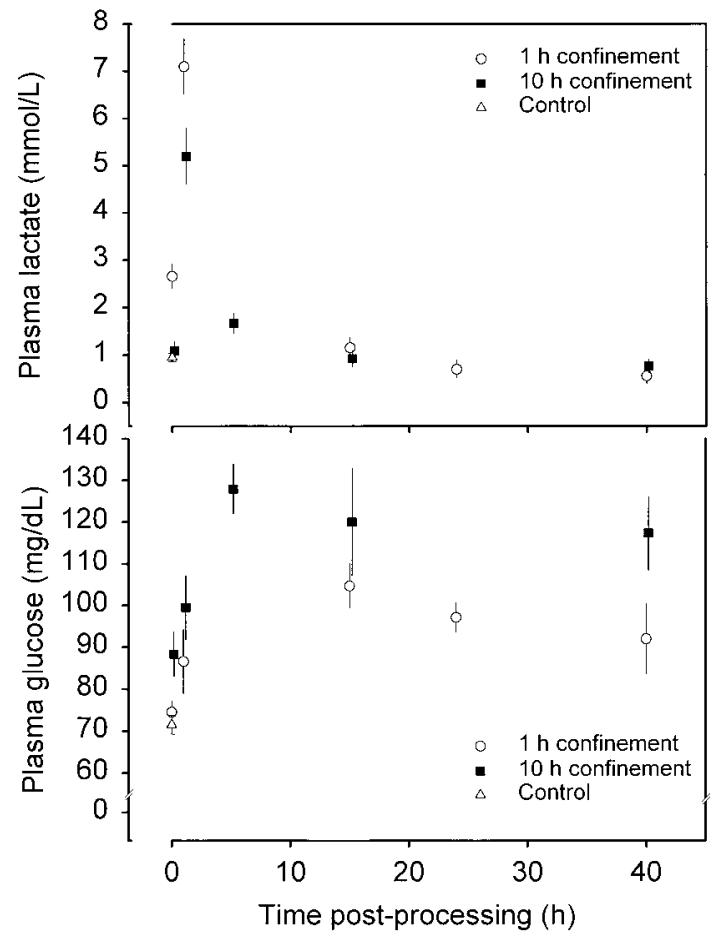

FIGURE 2.-Plasma lactate (upper panel) and glucose (lower panel) concentrations (mean $\pm \mathrm{SE}$ ) in rainbow trout (males and females combined) during recovery from trapping after 1 or $10 \mathrm{~h}$ of confinement; control fish were not confined and were angled downstream of the barrier and trap. Concentrations at the end of confinement are shown as $0 \mathrm{~h}$. All fish were from the Whitikau Stream in northern New Zealand.

confined for $1 \mathrm{~h}$ compared with those that had been confined for $10 \mathrm{~h}(F=5.100, \mathrm{df}=21, P=0.035)$. Plasma lactate levels in the two treatment groups were not significantly different from each other or from controls at 5, 15, 24, and $40 \mathrm{~h}$ where comparisons were possible.

In contrast to plasma cortisol and lactate profiles, plasma glucose concentrations during recovery were not significantly different between the 1and 10-h confinement treatments, although fish that were confined for $1 \mathrm{~h}$ tended to have lower levels of plasma glucose (Figure 2B). However plasma glucose concentrations did change significantly during the recovery period ( $1 \mathrm{~h}: F=7.564$, $\mathrm{df}=75 ; 10 \mathrm{~h}: F=10.681$, df $=70)$. Following a 10-h confinement and processing, mean glucose concentrations increased to a measured peak at 5 h of recovery $(P=0.003)$. Plasma glucose concentrations tended to decline slightly between 15 and $40 \mathrm{~h}$ in both groups, but remained elevated above control concentrations at $40 \mathrm{~h}$ after pro- cessing in both treatment groups ( $1 \mathrm{~h}: P=0.039$; 10 h: $P<0.001)$.

\section{Stress Response in Prespawning versus Postspawning Fish}

For postspawning fish there were no sex-specific differences in the cortisol concentration of the controls $(F=1.33, \mathrm{df}=20, P=0.262)$ or extreme stressor fish $(F=2.01$, df $=21, P=0.172)$.

Following the extreme stressor treatment the plasma cortisol concentration in kelts was significantly lower than in prespawning fish (three-way ANOVA: main effect $F=33.277$, df $=88$; males, $P<0.001$; females, $P<0.001)$. Notwithstanding this, postspawning fish were able to elevate plasma cortisol concentrations significantly following the extreme stressor treatment (three-way ANOVA: main effect $F=158.583$, df $=88$; males, $P=$ 0.015 females, $P=0.001$ ).

Plasma lactate was not different between prespawning and postspawning control fish. However, following the extreme stressor, the concentration in kelts was significantly lower than in prespawning fish (two-way ANOVA: main effect $F=$ 11.139, df $=85, P<0.001$ ). Postspawning fish were still able to elevate plasma lactate concentrations significantly (two-way ANOVA: main effect $F=74.647$, df $=85, P<0.001$ ) following the extreme stressor treatment. In contrast, there was no increase in plasma glucose concentrations in kelts during the extreme stressor treatment (twoway ANOVA: main effect $F=16.936$, df $=84$, $P=1.0)$.

\section{Discussion}

This study illustrates that the trapping of wild rainbow trout elicits a stress response. To our knowledge this is the first time that the response of wild trout to this trapping has been documented in situ. The stress response indicators in our study were chosen to give an indication of psychological and metabolic stressors that are imposed by trapping. Given the well documented effects of the stress response on overall health and fitness, these findings suggest that care should be taken to minimize disrupting fish during and after trapping, particularly during critical life stages such as reproduction.

The control concentrations of plasma cortisol measured in females in our study $(21.4 \mathrm{ng} / \mathrm{mL})$ were similar to those reported for wild rainbow trout caught by the same method about $10 \mathrm{~km}$ downstream of the trap $(18.8 \mathrm{ng} / \mathrm{mL}$; Pankhurst and Dedual 1994). The significantly lower basal 
levels in males $(6.1 \mathrm{ng} / \mathrm{mL})$ suggest that the process of sexual maturation may modify the HPI axis in rainbow trout. Similarly, the magnitude of the stress response in our study was much greater in females than males. Sex-specific differences in the cortisol response to a stressor have been reported (Sumpter et al. 1987; Pottinger et al. 1995), although this appears to be the first time such differences have been observed in a wild population of rainbow trout.

The trapping procedure may be viewed conceptually as a multiple stressor environment. A fish passing through the trap must deal with several challenges, the first of which occurs at the barrier. Data from this study indicate that blocking the upstream migration produced a significant stress response. It may be that the barrier constituted a psychological stressor (Specker and Schreck 1980), given the fish's motivation to move upstream to spawn, which elevated cortisol levels. An alternative explanation is that the increased swimming activity and frequent bouts of burst swimming associated with finding passage through the barrier caused the increase in cortisol. Plasma lactate concentrations tended to be higher in fish that had been working the barrier, but probably the bulk of the lactate produced was released from muscle tissue during the first hour of confinement. Whether exhaustive exercise alone increases plasma levels of cortisol remains unresolved. This is due to the inherent difficulties of exercising fish without exposing them to factors that may in themselves induce a stress response. It would be illuminating to compare these results with levels in fish that have passed through a natural barrier. Perhaps the elevated cortisol may mobilize energy so that the fish can swim past the barrier.

Once fish entered the cage, the level of activity appeared to be relatively low and burst swimming was not observed. Basal levels of plasma lactate were achieved within at least $5 \mathrm{~h}$ indicating that the fish were no longer in oxygen debt. Plasma cortisol remained elevated throughout confinement in both sexes; the lower levels in the 10 -h versus 1 -h females most likely represents acclimation to the chronic stress of confinement.

At the end of the confinement, fish were processed. This resulted in significant elevations in plasma cortisol, lactate, and glucose. Data from our study tend to indicate that processing and confinement represent different stressors to the fish. Fish that were processed as soon as they entered the trap, to avoid a stress response due to confinement, had significantly lower concentrations of plasma cortisol and significantly higher levels of plasma lactate after $1 \mathrm{~h}$ than did fish confined in the cage for $1 \mathrm{~h}$ and not processed. This is probably due to the nature of the stressor because processing involves air exposure and handling, whereas confinement is more of a psychological stressor. During recovery, plasma cortisol in females confined for $1 \mathrm{~h}$ peaked after $15 \mathrm{~h}$ of recovery, although the actual peak probably was sometime before this, given that the measured peak in fish confined for $10 \mathrm{~h}$ was at $5 \mathrm{~h}$ postprocessing. This level is approximately five-fold higher than levels measured previously in rainbow trout in response to capture by angling (Pankhurst and Dedual 1994) or acute handling or confinement (Pickering et al. 1991). Plasma glucose, and in most cases plasma cortisol, concentrations remained elevated after $40 \mathrm{~h}$ of recovery in our study. Obtaining plasma from recovering fish in the field is extremely difficult without confining the fish in some manner; thus, we cannot rule out the possibility that fish were subject to chronic stress by the confinement during their recovery. We think this is unlikely, however, because the low levels of plasma lactate after $5 \mathrm{~h}$ suggest that the fish were not trying to escape from the recovery area. The design of the enclosures was such that fish would have had to expend considerable energy in reaching the block at the head of the pool. Given this we would have expected to see higher levels of plasma lactate at 15, 24, and $40 \mathrm{~h}$, if the fish were working the upstream end of the recovery pool. Furthermore, no observations of fish at the upstream end of the recovery enclosure were made. In addition, we often observed Floy-tagged fish holding in a large pool directly above the trap for some time before continuing their migration. This is consistent with results on the Columbia River for juvenile salmonids that have been stressed (C. Schreck, Oregon Cooperative Fish and Wildlife Research Unit, personal communication) and with the hypothesis that migration is inhibited during the stress response. These observations are in agreement with our interpretation that fish in the recovery areas may not have been trying to migrate, and thus, the response during this time represents recovery and not the response to a chronic confinement stressor.

Multiple acute disturbances have been shown to lengthen the time to recovery of plasma cortisol in chinook salmon O. tshawytscha (Barton et al. 1986). In our study fish were subject to three acute stressors, which may explain the extended recovery period relative to other studies. Furthermore, the duration of confinement significantly affected 
the magnitude and duration of the stress response. Data for plasma cortisol, lactate, and glucose suggest that short confinement periods before processing do not allow the fish to acclimate to the confinement stressor, thus compounding the effects of processing. The significance of these observations is unclear because there is no data to suggest whether managers should minimize the length of disturbance or the magnitude of the stress response.

The postspawning fish we sampled clearly showed a reduced ability to undergo a stress response compared with mature, prespawning fish. However, caution must be exercised in interpreting these and other results because the correlation between the magnitude of the response and the biological impairment is unknown. Although prespawning males and females differed in their control and stressor-induced concentrations of plasma cortisol, that difference was not found in kelts. Kelts of both sexes had significantly lower concentrations of plasma cortisol, lactate, and glucose than prespawning fish following the extreme stressor. Egg or sperm production in fishes results in depletion of a number of constituents (e.g., carbohydrates, proteins, lipids, and inorganic ions), and this process is exaggerated in migratory fish that ascend rivers to spawn. In many salmonids further depletion results from the concurrent lack of feeding (Love 1970). It is possible that migration, territory defense, and redd building increase basal metabolic demands, which subsequently decrease metabolic capacity following spawning.

Our results suggest that fisheries managers consider each aspect of a trapping operation to minimize the stress response of fish. At the barrier, providing cues for passage, such as increased flow through the breaks and structures, to guide fish in the appropriate direction may minimize the disruption to the migration. However, we cannot suggest any action for reducing the stress response caused by confinement and processing. Leaving fish in the trap longer allowed them to acclimate to the confinement and thus reduced the magnitude of the stress response and duration of recovery following processing. However, it is more likely that densities will increase if fish are held longer, which in turn, could increase the stress response because of crowding and the increased time taken to process the fish. We also have data suggesting that the length of disturbance due to processing correlates significantly with increased plasma concentrations of cortisol and lactate. This suggests that it is important to minimize the length of dis- turbance during processing. Therefore the optimal strategy appears to favor processing fish as soon as they enter the trap, but this is very laborintensive. In addition, it also appears that it is important to minimize the disturbance to postspawning fish. Given the inability of these fish to initiate a metabolic response to a severe stressor, these fish must be considered close to the their physiological tolerance limits.

In conclusion, it is clear that trapping results in a significant stress response in wild rainbow trout. The magnitude and in some cases the duration of the stress response was generally much greater than has been previously reported. The consequences of such an event on growth, reproduction, and ultimately survival of the adult fish and their progeny need to be determined. Therefore, we suggest that trapping operations of spawning-run fish should be carried out only when there is no alternative method for obtaining data on a fishery.

\section{Acknowledgments}

The authors gratefully acknowledge the help of Iain Maxwell and fellow Department of Conservation (DOC) staff in New Zealand for field assistance. This research was carried out as part of S. Clements' Master of Science degree, and was funded in part by the DOC and the University of Waikato. The Animal Ethics Committee at the University of Waikato approved all manipulations.

\section{References}

Adams, S. M., J. E. Breck, and R. B. McLean. 1985. Cumulative stress-induced mortality of gizzard shad in southeastern U.S. reservoir. Environmental Biology of Fishes 13:103-112.

Barton, B. A., C. B. Schreck, and L. A. Sigismondi. 1986. Multiple acute disturbances evoke cumulative physiological stress responses in juvenile chinook salmon. Transactions of the American Fisheries Society 115:245-251.

Carmichael, G. J. 1984. Long distance truck transport of intensively reared largemouth bass. Progressive Fish-Culturist 46:111-115.

Donaldson, E. M. 1981. The pituitary-interrenal axis as an indicator of stress in fish. Pages 11-47 in A. D. Pickering, editor. Stress and fish. Academic Press, London.

Ingram, J. R., L. R. Mathews, and R. M. McDonald. 1994. Remote blood sampling device: a stress-free blood sampling technique for free ranging animals. Proceedings of the New Zealand Society of Animal Production 54:39-42.

Love, R. M. 1970. The chemical biology of fishes. Academic Press, London.

Pankhurst, N. W., and M. Dedual. 1994. Effects of capture and recovery on plasma levels of cortisol, lac- 
tate and gonadal steroids in a natural population of rainbow trout. Journal of Fish Biology 45:10131025.

Pickering, A. D., and T. G. Pottinger. 1987. Poor water quality suppresses the cortisol response of salmonid fish to handling and confinement. Journal of Fish Biology 20:229-244.

Pickering, A. D., T. G. Pottinger, J. P. Sumpter, J. F. Carragher, and P. Y. Le Bail. 1991. Effects of acute and chronic stress on the levels of circulating growth hormone in the rainbow trout, Oncorhynchus mykiss. General and Comparative Endocrinology 83:86-93.

Pottinger, T. G., P. H. M. Balm, and A. D. Pickering. 1995. Sexual maturity modifies the responsiveness of the pituitary-interrenal axis to stress in male rainbow trout. General and Comparative Endocrinology 98:311-320.

Sigismondi, L. A., and L. J. Weber. 1988. Changes in avoidance response time of juvenile chinook salmon exposed to multiple acute handling stresses. Transactions of the American Fisheries Society 117:196201.

Specker, J. L., and C. B. Schreck. 1980. Stress responses to transportation and fitness for marine survival in coho salmon (Oncorhynchus kisutch) smolts. Journal of the Fisheries Research Board of Canada 37: 765-769.

SPSS. 2000. SYSTAT 10 Statistics I. SPSS, Chicago. Sumpter, J. P., T. J. Benfey, and H. M. Dye. 1986. The effects of stress on plasma ACTH, $\alpha-\mathrm{MSH}$, and cortisol levels in salmonid fishes. General and Comparative Endocrinology 62:377-385.

Sumpter, J. P., J. F. Carragher, T. G. Pottinger, and A. D. Pickering. 1987. The interaction of stress and reproduction in trout. Pages 299-302 in D. R. Idler, L. W. Crim, and J. M. Walsh, editors. Reproductive physiology of fish. Memorial University Press, St. John's, Newfoundland.

Wendelaar-Bonga, S. E. 1997. The stress response in fish. Physiological Reviews 77:591-625. 